OPEN ACCESS

Edited by: Elodie Segura, Institut Curie, France

Reviewed by: Christelle Faveeuw, INSERM U1019 Centre d'Infection et Immunité de Lille (CIIL), France Salvador Iborra, Universidad Complutense de Madrid, Spain

*Correspondence: Tae Sung Kim tskim@korea.ac.kr

Specialty section: This article was submitted to Antigen Presenting Cell Biology, a section of the journal

Frontiers in Immunology

Received: 12 June 2020 Accepted: 18 September 2020 Published: 14 October 2020

Citation:

Jung $H$-J, Park S-H, Cho K-M, Jung KI, Cho D and Kim TS (2020) Threonyl-tRNA Synthetase Promotes

T Helper Type 1 Cell Responses

by Inducing Dendritic Cell

Maturation and IL-12 Production via an NF- $\kappa B$ Pathway.

Front. Immunol. 11:571959. doi: 10.3389/fimmu.2020.571959

\section{Threonyl-tRNA Synthetase Promotes T Helper Type 1 Cell Responses by Inducing Dendritic Cell Maturation and IL-12 Production via an NF-kB Pathway}

\author{
Hak-Jun Jung ${ }^{1}$, Su-Ho Park ${ }^{1}$, Kyung-Min Cho ${ }^{1}$, Kwang II Jung ${ }^{1}$, Daeho Cho ${ }^{2}$ \\ and Tae Sung Kim ${ }^{*}$ \\ 1 Department of Life Science, College of Life Science and Biotechnology, Korea University, Seoul, South Korea, ${ }^{2}$ Institute of \\ Convergence Science, Korea University, Seoul, South Korea
}

Threonyl-tRNA synthetase (TRS) is an aminoacyl-tRNA synthetase that catalyzes the aminoacylation of tRNA by transferring threonine. In addition to an essential role in translation, TRS was extracellularly detected in autoimmune diseases and also exhibited pro-angiogenetic activity. TRS is reported to be secreted into the extracellular space when vascular endothelial cells encounter tumor necrosis factor- $\alpha$. As T helper (Th) type 1 response and IFN- $\gamma$ levels are associated with autoimmunity and angiogenesis, in this study, we investigated the effects of TRS on dendritic cell (DC) activation and CD4 T cell polarization. TRS-treated DCs exhibited up-regulated expression of activation-related cell-surface molecules, including CD40, CD80, CD86, and MHC class II. Treatment of DCs with TRS resulted in a significant increase of IL-12 production. TRS triggered nuclear translocation of the NF- $\mathrm{KB}$ p65 subunit along with the degradation of $1 \kappa B$ proteins and the phosphorylation of MAPKs in DCs. Additionally, MAPK inhibitors markedly recovered the degradation of $\mathrm{I}_{\mathrm{K}} \mathrm{B}$ proteins and the increased IL-12 production in TRS-treated DCs, suggesting the involvement of MAPKs as the upstream regulators of NF- $\mathrm{KB}$ in TRSinduced DC maturation and activation. Importantly, TRS-stimulated DCs significantly increased the populations of IFN- $\gamma^{+} \mathrm{CD} 4 \mathrm{~T}$ cells, and the levels of IFN- $\gamma$ when co-cultured with $\mathrm{CD} 4^{+} \mathrm{T}$ cells. The addition of a neutralizing anti-IL-12 mAb to the cell cultures of TRStreated DCs and $\mathrm{CD} 4^{+} T$ cells resulted in decreased IFN- $\gamma$ production, indicating that TRSstimulated DCs may enhance the Th1 response through DC-derived IL-12. Injection of OT-II mice with OVA-pulsed, TRS-treated DCs also enhanced Ag-specific Th1 responses in vivo. Importantly, injection with TRS-treated DC exhibited increased populations of IFN$\gamma^{+}-\mathrm{CD}^{+}$and $-\mathrm{CD}^{+} \mathrm{T}$ cells as well as secretion level of IFN- $\gamma$, resulting in viral clearance 
and increased survival periods in mice infected with influenza A virus (IAV), as the Th1 response is associated with the enhanced cellular immunity, including anti-viral activity. Taken together, these results indicate that TRS promotes the maturation and activation of DCs, DC-mediated Th1 responses, and anti-viral effect on IAV infection.

Keywords: aminoacyl-tRNA synthetase, threonyl-tRNA synthetase, dendritic cell, interleukin-12, type 1 helper T cells, interferon- $\gamma$, influenza A virus

\section{INTRODUCTION}

Aminoacyl-tRNA synthetases (aaRSs) are enzymes related to aminoacylation that cognate amino acid to a specific-tRNA. The aaRSs constitute 20 differential types, each transferring a specific amino acid. In addition to the essential function catalyzing aminoacylation function, some of the aaRSs are secreted into the extracellular environment, similar to cytokines, in specific conditions, and have various non-canonical functions. These include the control of transcription, translation (1) and RNA processing (2), as well as anti-viral immunity $(3,4)$, angiogenesis (1) tumorigenesis (5), metastasis (6), apoptosis, and immune response (6-8) including pro-inflammatory effect $(9,10)$.

Threonyl-tRNA synthetase (TRS) is a class II aaRS that charges threonine to threonine-specific tRNA. TRS has been associated with autoimmune diseases, such as polymyositis and dermatomyositis, as demonstrated by the presence of the myositis autoantibody PL-7 $(11,12)$. TRS is secreted into the extracellular space when vascular endothelial cells are exposed to tumor necrosis factor- $\alpha$ (TNF- $\alpha$ ) or vascular endothelial growth factor (VEGF) associated with an angiogenetic environment. Secreted TRS can induce endothelial cell migration and angiogenesis (13) as well as pancreatic cancer cell migration (14). However, the effect of TRS on immunity involving dendritic cells (DCs) and DC-mediated T cell response remains unknown.

Dendritic cell is a type of professional antigen-presenting cells (APCs) that link innate and adaptive immunity. Activated and matured DCs exhibit characteristic phenotypic changes including the upregulation of the expression of MHC II and costimulatory molecules, such as CD40, CD80 and CD86. Moreover, mature DCs can secret various cytokines and chemokines (15) Naïve CD4 T cells can be differentiated through direct interaction with mature DCs, as well as by indirect communication by secreted various cytokines from DCs $(16,17)$. In addition, matured DCs induce the polarization of $\mathrm{CD}^{+} \mathrm{T}$ cell to $\mathrm{T}$ helper (Th) subsets, such as Th1, Th2, Th17 and regulatory $\mathrm{T}$ cell $\left(\mathrm{T}_{\text {reg }}\right)$, under each polarizing condition containing specific cytokines (15) Th1 cells can be differentiated by interleukin (IL)-12 from DCs, and activated Th1 cells secrete a large amount of interferon- $\gamma($ IFN- $\gamma)$ which is related in the upregulation of the cellular immune response and the clearance of pathogens, such as virus and bacteria $(18,19)$. Th2 cells produce IL-4, IL-5 and IL-13,

Abbreviations: aaRS, aminoacyl-tRNA synthetase; DC, dendritic cell; IAV, influenza A virus; IFN- $\gamma$, interferon-gamma; LPS, lipopolysaccharide; MFI, mean fluorescence intensity; OVA, ovalbumin; PMB, polymyxin B; TRS, threonyl-tRNA synthetase. which are critical for many diseases including rhinitis, asthma and atopic dermatitis (20). IL-17-secreting Th17 cells induce immune responses against self-antigens and autoimmune disease such as rheumatoid arthritis and systemic lupus erythematosus (21). In contrast, Foxp3-positive $\mathrm{T}_{\text {reg }}$ cells are directly involved in the regulation of immune response to pathogens, allergens, and self-antigens by tolerance and downregulation of effector $\mathrm{T}$ cells (22).

IFN- $\gamma$ is the type II of IFNs that have essential role in combating virus infection and regulating the antiviral immune response (23). IFN- $\boldsymbol{\gamma}$ induces the antiviral immunity via regulation of the innate immune response and activation of adaptive immunity (18) against Ebola virus (24), Hepatitis B virus (25), Dengue virus (26), and Influenza A virus (IAV) (19).

Here, we report novel non-canonical functions of TRS whereby it induces the maturation and activation of DCs with Th1-polarizing ability and anti-viral activity. TRS induced the activation and maturation of bone marrow-derived DCs, as well as primary splenic DCs. TRS-activated DCs promoted Th1 responses in vitro and in vivo. Importantly, administration of TRS-stimulated DCs upregulated the populations of IFN- $\boldsymbol{\gamma}$ secreting $\mathrm{CD}^{+}$and $\mathrm{CD}^{+} \mathrm{T}$ cells as well as secretion level of IFN- $\gamma$ and induced viral clearance in influenza-infected mice. These results may explain the role of TRS in autoimmunity and angiogenesis, as well as its anti-viral activity.

\section{MATERIALS AND METHODS}

\section{Mice}

Female C57BL/6N mice at 7-10 weeks of age were purchased from Orient Bio (Kapyong, Korea) and ovalbumin (OVA)specific OT-II transgenic mice on a C57BL/6 background were purchased from Jackson Laboratory (Bar Harbor, Maine, USA). All mice were housed under specific pathogen-free conditions. All animal experiments were conducted according to the Korea University Guidelines for the Care and Use of Laboratory Animals (approval No. KUIACUC-2019-0013).

\section{Reagents and Cytokines}

Cells were cultured in RPMI 1640 medium (Thermo Scientific, Rockford, IL) with 10\% FBS (Capricon Scientific, Germany), 100 $\mathrm{U} / \mathrm{ml}$ penicillin, $100 \mu \mathrm{g} / \mathrm{ml}$ streptomycin, $10 \mathrm{mM}$ HEPES (Life Technologies BRL, Rockville, MD, USA), and $50 \mu \mathrm{M} 2$ mercaptoethanol (Sigma-Aldrich, St Louis, MO). Recombinant mouse GM-CSF was obtained from ProSpec (Rehovort, Israel). Recombinant human Flt3L was obtained from Biolegend 
(California, USA). Recombinant TRS was overexpressed as a His tag fusion protein in IPTG-induced Escherichia coli BL21 (DE3) and purified by nickel affinity chromatography, followed by a HiTrap Q column (GE Healthcare, 17-5156-01) for anion exchange chromatography. The eluent was further purified by gel filtration chromatography using Superdex75 16/600 (GE Healthcare, 28-9893-33) to further remove residual LPS. The level of endotoxin in each purification lot was determined using a Toxinsensor ${ }^{\mathrm{TM}}$ chromogenic LAL endotoxin assay kit (Genscript, Nanjing, China). Lots containing $<0.05 \mathrm{EU} / \mu \mathrm{g}$ protein were used for this study. Anti-phospho-ERK, anti-ERK, anti-p38, anti-

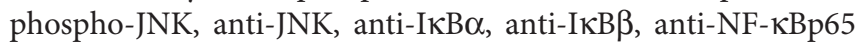
and anti-GAPDH Abs were from Santa Cruz Biotechnology (Dallas, TX). Anti-phospho-p38 Abs and anti-phospho-NFผBp65 was purchased from Cell Signaling Technology (Beverly, MA). Anti-6X His tag Abs was purchased from Abcam (Cambridge, UK). Alexa Fluor 488-labeled anti-rabbit IgG and Alexa Fluor 488-labeled anti-mouse IgG were purchased from Molecular Probes (Eugene, OR). ERK inhibitor (U0126) was purchased from AbMole BioScience. NF- $\kappa B$ inhibitor (CAPE), IKK/IKB inhibitor (IKK-16), p38 inhibitor (SB203580), JNK inhibitor (SP 600125), OVA, LPS (from E. coli 0111:B4), PMA, and ionomycin were purchased from Sigma-Aldrich. Golgiplug containing Brefeldin A and antimouse IL-12p40/p70 (C17.8) were purchased from BD Biosciences (San Diego, CA).

\section{Generation of Bone Marrow-Derived DCs and Splenic DCs}

The femurs and tibiae of C57BL/6 mice were cut and the marrows were flushed with ice-cold RPMI 1640 medium using syringe that was equipped with a 26-gauge needle. RBCs were lysed with RBC lysis buffer from Biovision (Milpitas, CA). The bone marrow cells were then suspended in growth medium. The number of cells was adjusted to $4 \times 10^{6}$ cells/well $(10 \mathrm{ml})$, and then added to petri dishes. The cells were cultured in RPMI 1640 medium containing $10 \% \mathrm{FBS}, 100 \mathrm{U} / \mathrm{ml}$ penicillin, $100 \mu \mathrm{g} / \mathrm{ml}$ streptomycin, 10mM HEPES, and $50 \mu \mathrm{M} \beta$-mercaptoethanol supplemented with $20 \mathrm{ng} / \mathrm{ml}$ GM-CSF. The half of medium was renewed every other day, and the semi adherent cells were harvested on day 7 by gentle pipetting and used as immature GM-CSF-derived DCs. For Flt3L-derived DCs, BM cells were resuspended at $2 \times 10^{6} \mathrm{cell} / \mathrm{ml}$ in RPMI 1640 medium containing $200 \mathrm{ng} / \mathrm{ml}$ human recombinant FMS-like tyrosine kinase 3 ligand (Flt3L, Biolegend, 550602), plated at $5 \mathrm{ml} /$ well in 6 well plates and cultured for 9 days.

Splenic DCs were isolated from spleen cell suspensions using CD11c microbeads (CD11c MicroBeads UltraPure, Miltenyi Biotec) and MACS system (Miltenyi Biotec, San Diego, CA) with an MACS cell separator. CD11 ${ }^{+}$splenic DCs from C57BL/ 6 mice $\left(1.0 \times 10^{6}\right.$ cells/well $)$ were cultured for $20 \mathrm{~h}$ in a 24 -well plate with LPS $(500 \mathrm{ng} / \mathrm{ml})$ or TRS $(200 \mathrm{nM})$. The cells were thoroughly washed and used for phenotypic and functional characterization by flow cytometric analysis and the culture supernatants were used for determining IL-12 levels by enzyme-linked immunosorbent assay (ELISA).

\section{Flow Cytometric Analysis}

For cell surface molecules staining, DCs $\left(1 \times 10^{6}\right.$ cells/well $)$ were harvested, washed with FACS washing buffer (0.5\% FBS and filtered $0.05 \% \mathrm{NaN}_{3}$ in PBS). The cells were then labeled for $20 \mathrm{~min}$ at room temperature with APC-conjugated anti-mouse CD11c (N418) and one of the following PE-conjugated mAbs: anti-mouse IA ${ }^{\mathrm{b}}$ (AF6-120.1; MHC II), anti-mouse CD40 (3/23), anti-mouse CD80 (16-10A1) and anti-mouse CD86 (GL1) The mean fluorescence intensity (MFI) of each surface molecules was measured from the total cell population via BD accuri C6 plus flow cytometer (BD Biosciences). For intracellular staining, cells were stimulated for $5 \mathrm{~h}$ with $50 \mathrm{ng} / \mathrm{ml}$ of PMA, $1 \mu \mathrm{g} / \mathrm{ml}$ of ionomycin and Golgiplug. The cells were harvested, washed with FACS buffer and stained with FITC-conjugated anti-mouse CD4 (RM4-5) for $20 \mathrm{~min}$ at room temperature. The cells were fixed for 20 min using a Cytocfix/Cytoperm kit (BD Biosciences). Intracellular cytokines were detected with APC-conjugated antimouse IFN- $\gamma$ (XMG1.2) and IL-17 (eBio17B7), PE-conjugated anti-mouse IL-4 (11B11). Treg cells were firstly stained with FITC-conjugated anti-mouse CD4 (RM4-5) and PE-conjugated anti-mouse CD25 (PC61), followed by APC-conjugated antimouse FoxP3 (FJK-16s) according to the manufacturer's instructions of FoxP3 staining buffer set (eBioscience, San Jose, CA).

\section{Reverse Transcription Polymerase Chain Reaction}

Total mRNA was extracted from the DCs $\left(3 \times 10^{6}\right.$ cells/well) by using RiboEX reagent (GeneAll Biotechnology, Korea) according to the manufacturer's protocol. Total RNA was reverse transcribed into cDNA with CycleScript reverse transcriptase (Bioneer) and amplified by PCR. After PCR amplification, the products were separated on $1.5 \%$ agarose gels and stained with ethidium bromide. Primer sequences used in this study are: mouse $I L-1 \beta$ (forward, 5'-CTGAAGCAGCTATGGCAACT-3'; reverse, 5'-ACAGGACAGGTATAGATTC-3'), IL-6 (forward, 5' - TGAACAACGA TGA TGCACTT - 3'; reverse, 5' CGTAGAGAACAACATAAGTC-3'), IL-12p35 (forward, 5' TCAGCGTTCCAACAGCCTC-3'; reverse, 5' - TAAA ACGCAGCTCAG TAACAGTCCG-3'), IL-12p40 (forward, 5' CAGAAGCTAACCATCTCCTGGTTTG-3'; reverse, 5' TCCGGAGTAATTTGGTGCTTCACAC-3'), TNF- $\alpha$ (forward, 5'-GGCAGGTCTACTTTGG AGTCATTG-3'; reverse, 5' ACATTCGAGGCTCCAGTGAATTTCGG- $3^{\prime}$ ), TGF- $\beta$ (forward, 5'-TATAGCAACAATTCCTGGCG T-3'; reverse, 5'TCCTAAAGTCAATGTACAGCT-3'), GAPDH (forward, 5'ACATCAAGAAGGTGGTGAAG- 3'; reverse, 5'-ATT CAAGAGAGTAGGGAGGG-3’).

\section{Enzyme-Linked Immunosorbent Assay}

The concentrations of IL-12p40, IL-12p70, IL-4, and IL-17 in the culture supernatants were measured in triplicate using ELISA kit (eBioscience, San Diego, CA). The level of IFN- $\gamma$ was quantified with specific murine anti-IFN- $\gamma$ HB170 coating and biotinylated anti-IFN- $\gamma$ XMG1.2 mAbs and the standard curve was generated using recombinant IFN- $\gamma$ (BD Bioscience). The wells were finally 
washed again with PBST (0.05\% Tween-20 in PBS) and $o$-phenylenediamine (OPD) containing citrate and $\mathrm{H}_{2} \mathrm{O}_{2}$ was added to each well and incubated for $20 \mathrm{~min}$ at room temperature. To stop the reaction, $2 \mathrm{~N} \mathrm{H}_{2} \mathrm{SO}_{4}$ was added to each well. Developed colors were detected on a VMax kinetic microplate reader at $490 \mathrm{~nm}$. The measurement was performed in triplicate.

\section{Immunofluorescent Staining}

DCs $\left(3 \times 10^{5}\right.$ cells/well) were fixed with $4 \%$ paraformaldehyde and blocked with $0.1 \%$ Triton X-100 and $0.5 \%$ BSA in PBS for $30 \mathrm{~min}$ at RT. The cells were incubated with rabbit anti-NFผBp65 (1:300 dilution) and mouse Anti-6X His tag Abs (1:300 dilution), at $4^{\circ} \mathrm{C}$ overnight, followed by staining with Alexa Fluor 488-conjugated anti-rabbit IgG Ab (1:300 dilution) and Alexa Fluor 488-conjugated anti-mouse IgG Ab (1:300 dilution) for $1 \mathrm{~h}$ at RT. Actin were counterstained with Rhodamine phalloidin (Molecular Probes, 1:200 dilution) for $1 \mathrm{~h}$ at RT. Nuclei were counterstained with DAPI (Molecular Probes, $3 \mu \mathrm{M}$ ) for $3 \mathrm{~min}$ and observed with a confocal laser scanning microscope (LSM 800, Carl Zeiss, Oberkochen, Germany).

\section{Western Blot Analysis}

DCs $\left(5 \times 10^{6}\right.$ cells/well) were harvested at the indicated time points, washed with PBS, and lysed in RIPA buffer containing protease and phosphatase inhibitor cocktail. The whole cell lysates were then separated on 10\% SDS-PAGE and transferred to nitrocellulose membranes. The membranes were blocked with $4.5 \%$ BSA for $1 \mathrm{~h}$, and incubated overnight at $4^{\circ} \mathrm{C}$ with respective Abs against phosphorylated p38, JNK, ERK, I $\mathrm{B} \alpha \alpha, \mathrm{I} \kappa \mathrm{B} \beta, \mathrm{NF}-\kappa \mathrm{Bp} 65$ or GAPDH. The membranes were then treated with HRP-conjugated anti-mouse IgG or anti-rabbit IgG at room temperature and the bands were visualized with chemiluminescent HRP substrate (Millipore Corporation, Billerica, MA) and X-Ray film processor (JP-33, JPI, Seoul, Korea).

\section{$\mathrm{CD4}^{+} \mathrm{T}$ Cell Isolation and Th Subtype Polarization In Vitro and In Vivo}

$\mathrm{CD}^{+} \mathrm{T}$ cells were isolated from lymph nodes of mice by magnetic bead purification (MACS, Miltenyi Biotec.), and purity was $>95 \%$. For in vitro experiments of Th cell polarization, purified $\mathrm{CD}^{+} \mathrm{T}$ cells $\left(1 \times 10^{5}\right.$ cells $)$ were incubated for 2 or 3 days with anti-CD3 Ab and anti-CD28 Ab $(1 \mu \mathrm{g} / \mathrm{ml})$ in the presence of specific polarizing cytokines of each Th subset as follows: IL-12p70 (10 ng/ml) and anti-IL-4 (20 ng/ $\mathrm{ml})$ for Th1, IL-4 (20 ng/ml) and anti-IFN- $\gamma(20 \mathrm{ng} / \mathrm{ml})$ for Th2; TGF- $\beta$ (2 ng/ml), IL-6 (20 ng/ml), anti-IL-4 (20 ng/ml) and antiIFN- $\gamma(20 \mathrm{ng} / \mathrm{ml})$ for Th17; TGF- $\beta(2 \mathrm{ng} / \mathrm{ml})$ for Treg polarization. For the in vitro syngeneic co-culture of $\mathrm{CD}^{+} \mathrm{T}$ cells and DCs, isolated CD $4^{+} \mathrm{T}$ cells $\left(5 \times 10^{5}\right.$ cells) from lymph node of OT-II mice were mixed with OVA-pulsed immature DCs, or OVA-pulsed LPS- or TRS-treated DCs ( $5 \times 10^{4}$ cells) at a ratio of 10:1. Three days later, the cell was harvested for analyzing populations of Th subsets, and the supernatant was collected for determining levels of IFN- $\gamma$, IL-4, and IL-17. The 7day cultured DCs from C57BL/6 mice were pulsed for $2 \mathrm{~h}$ with 10 $\mathrm{ng} / \mathrm{ml}$ OVA, after which the cells were incubated for $6 \mathrm{~h}$ with LPS $(500 \mathrm{ng} / \mathrm{ml})$ or TRS $(50,100$, and $200 \mathrm{nM})$. For in vivo polarization, OVA-pulsed, media-DCs, or TRS-treated DCs $\left(1 \mathrm{x} 10^{6}\right.$ cells) were adoptively transferred into OT- II mice by subcutaneous injection via footpads. Seven days later, CD4 ${ }^{+}$ $\mathrm{T}$ cells were collected form the draining lymph nodes and cultured in the presence of OVA $(100 \mathrm{ng} / \mathrm{ml})$.

\section{Immunization and Influenza Virus Infection}

Female 7-weeks-old C57BL/6 mice were immunized with DCs. The 7-day cultured immature DCs from C57BL/6 mice were pulsed for $3 \mathrm{~h}$ with $10 \mu \mathrm{g} / \mathrm{ml}$ hemagglutinin (HA) of influenza A/ WSN/1933 (Sino Bio, China), after which the cells were incubated for $24 \mathrm{~h}$ in the presence or absence of TRS (200 $\mathrm{nM})$. One day later, the cell was harvested and HA-pulsed, media-incubated DCs, or HA-pulsed, TRS-treated DCs (1 x $10^{6}$ cells) were injected into the mouse tail via intravenously (i.v.) injection. A negative control (MOCK) were also included. Three days after DC injection, mice were infected intranasally (i.n.) with $1 \mathrm{mLD}_{50}$ (mouse-lethal dose) of H1N1 IAV in $100 \mu \mathrm{l}$. H1N1 IAV were provided by Prof. Sang-Yun Choi $(27,28)$. All procedures were performed under isoflurane anesthesia. Virus infected mice were observed and weighed daily for 7 days. Total weight loss of $>30 \%$ were considered as humane endpoint.

\section{Plaque Assay}

Virus titration in the lung supernatants were detected by the standard plaque assay. The Monolayer Madin-Darby canine kidney (MDCK) cells were infected with 10-fold serially diluted lung supernatant for $1 \mathrm{~h}$ in Opti-MEM (Invitrogen) supplemented with $0.3 \%$ bovine serum albumin (BSA), $0.5 \mu \mathrm{g} /$ $\mathrm{ml}$ TPCK-treated trypsin and $1 \%$ antibiotics. After virus infection, the media were replaced with overlay media (L15 media containing $0.3 \% \mathrm{BSA}, 1 \mu \mathrm{g} / \mathrm{ml}$ TPCK-treated trypsin, $1 \%$ antibiotics, $1 \%$ glutamine, $2 \%$ high malting agarose). After incubation for $72 \mathrm{~h}$, MDCK cells were fixed with $4 \%$ formaldehyde for $1 \mathrm{~h}$. The overlay agarose was removed by flowing water and stained with $0.2 \%$ crystal violet solution. Viral titer were determined by counting the number of plaque.

\section{Analysis of Cell Populations in Bronchoalveolar Lavage Fluid}

Mice were anesthetized and bronchoalveolar lavage fluid (BALF) was collected by $1 \mathrm{ml}$ of PBS twice through the trachea. The BALF cells and lung lymphocytes were harvested, washed with FACS buffer and stained with FITC-conjugated anti-mouse CD4 (RM4-5) and CD8 (53-6.7) for $20 \mathrm{~min}$ at room temperature. The cells were fixed for $20 \mathrm{~min}$ using a Cytocfix/Cytoperm kit (BD Biosciences). Intracellular cytokines were detected with APCconjugated anti-mouse IFN- $\gamma$ (XMG1.2). The stained cells were analyzed by using FACS Accuri with Accuri C6 software (BD Biosciences).

\section{Statistical Analysis}

Statistical analysis was performed with unpaired Student's t-test for pairwise comparisons in SigmaPlot version 12.5 software (Systat Software Inc. Washington, USA) or one-way analysis of 
variance (ANOVA) with a Bonferroni post-test for multiple comparisons and using Kaplan-Meier method and a log-rank test (survival) and Mann-Whitney U test (body weight) in IBM SPSS Statistic 25 software (IBM. NY, USA). A $P$-values less than 0.05 were considered to be statistically significant. The data were presented as the means \pm SD or SEM of three independent experiments.

\section{RESULTS}

\section{TRS Induced the Activation and Maturation of Bone Marrow-Derived DCs}

When immature DCs are matured, they have the ability to activate and polarize $\mathrm{CD}^{+} \mathrm{T}$ cells via several signals, such as costimulatory molecules, MHC class molecules, and cytokines. To investigate whether TRS stimulated the expression of these maturation-related cell surface molecules on DCs, bone marrowderived DCs were incubated for $20 \mathrm{~h}$ in the presence or absence of TRS and the expression of the cell surface molecules was assessed by cytofluorometric analysis. TRS significantly increased the expression of MHC II and the costimulatory molecules CD40, CD80 and CD86 on CD11c ${ }^{+}$DCs in a dosedependent manner, as observed by the mean fluorescence intensity (MFI) values via cell cytometry. (Figures 1A, B).
To exclude the possibility of endotoxin contamination in TRS-mediated expression of cell surface molecules, DCs were pretreated with polymyxin $\mathrm{B}(\mathrm{PMB})$ to inhibit LPS signaling, followed by incubation with TRS or LPS. Treatment of DCs with PMB significantly inhibited the LPS-induced increase of the expression levels of all three surface molecules. However, PMB treatment did not affect the TRS-mediated expression of the cell surface molecules (Supplemental Figure 1A). In addition, the expression of cell surface molecules remained unchanged, similar to the case for the media-treated DCs, if the TRS protein was boiled for $30 \mathrm{~min}$ at $100^{\circ} \mathrm{C}$ before the treatment of the DCs (Supplemental Figure 1B), indicating that the TRS-mediated increase in the expression of cell surface molecules was not due to LPS contamination. Moreover, less than 0.05 endotoxin unit $/ \mathrm{mg}$ of protein ( 1 endotoxin unit $=0.1 \mathrm{ng} / \mathrm{ml} \mathrm{E}$. coli LPS) was detected, as determined by the Limulus Amebocyte lysate assay. These endotoxin concentrations proved insufficient for the activation of DCs.

Maturation and activation of DCs affect the expression of several genes, including cytokine genes. To investigate whether TRS stimulated the production of Th cell-polarizing cytokines from DCs, DCs were treated with TRS and the expression of the cytokines were determined at the mRNA and protein levels by reverse transcription polymerase chain reaction (RT-PCR) and ELISA. The mRNA levels of IL- $1 \beta$, IL- 6 , TNF- $\alpha$, TGF- $\beta$, IL$12 \mathrm{p} 35$, and IL-12p40 were significantly increased in TRS-treated

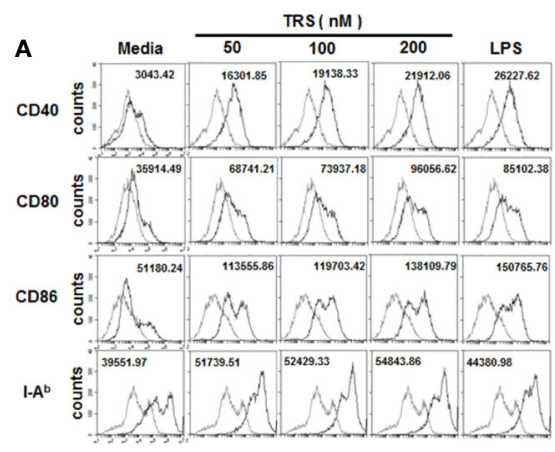

B
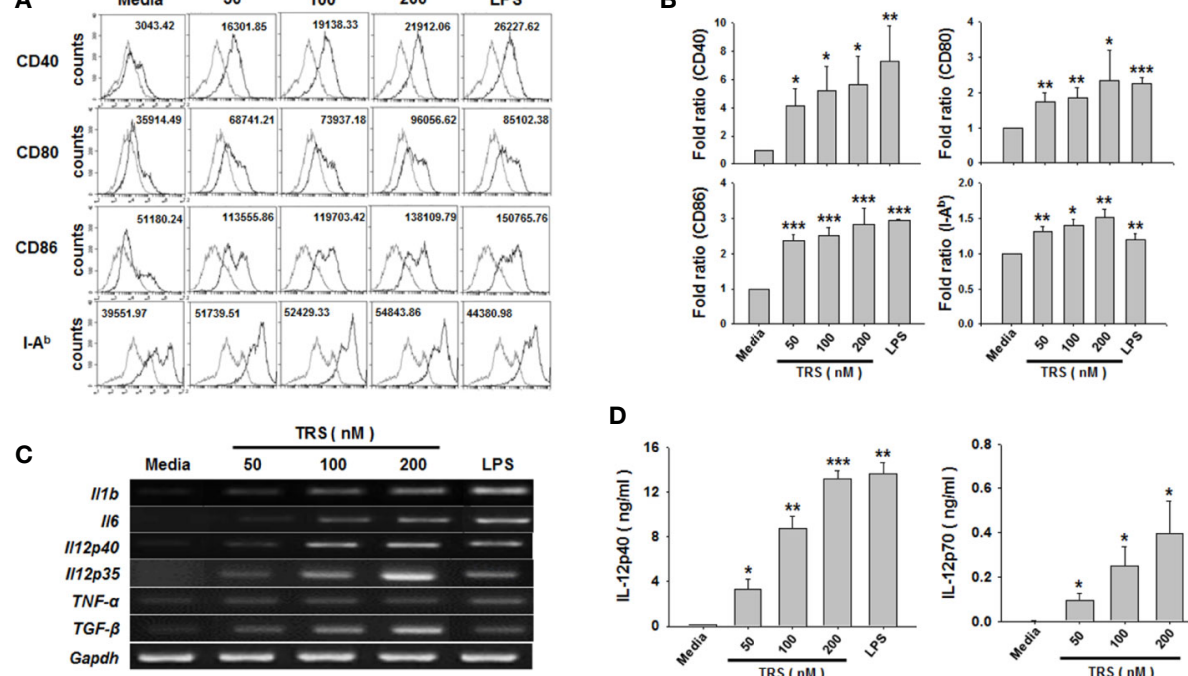

D

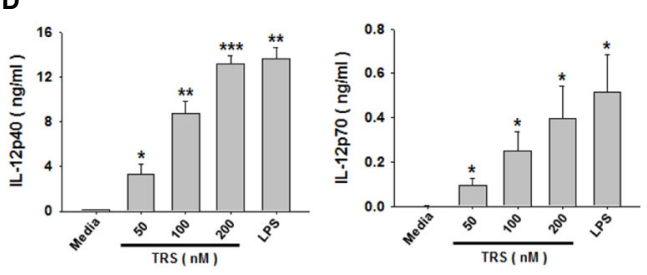

FIGURE 1 | Threonyl-tRNA synthetase (TRS) increases the expression levels of surface molecules and cytokines in bone marrow-derived dendritic cells (DCs). Bone marrow-derived DCs were isolated from C57BL/6 mice as described in the Materials and Methods. Immature-DCs (iDCs) were cultured for $20 \mathrm{~h}$ (A, D), or $6 \mathrm{~h}$ (C) with threonyl-tRNA synthetase (TRS; 50, 100, and $200 \mathrm{nM}$ ) or lipopolysaccharide (500 ng/ml). (A) The expression of CD40, CD80, CD86, and I-A molecules, as detected by flow cytometry for CD11 $\mathrm{c}^{+}$gated cells. Gray histograms, isotype control; black histograms, anti-CD40, anti-CD80, anti-CD86, and anti-I-A ${ }^{\mathrm{b}}$ Ab. Representative figures are presented. The value shown in the histograms represents the mean fluorescence intensity. (B) The fold ratio of surface molecules expression was plotted with the media-treated DCs as 1.0. The data represent mean \pm SD of three independent experiments $(n=3) ;{ }^{*} P<0.05$, ${ }^{\star \star} P<0.01$ and ${ }^{* \star \star} P<0.001$ compared with media-treated DCs. (C) mRNA levels of pro-inflammatory cytokines, as confirmed by reverse transcriptase-polymerase chain reaction. GAPDH is used as a control. (D) Levels of IL-12p40 and IL-12p70 in cell supernatants, as detected by enzyme-linked immunosorbent assay. Experiments were conducted three times independently and are represented as the mean \pm SEM of results performed in triplicate $(n=3)$. Statistical significance was assessed using unpaired Student's $t$-test; ${ }^{*} P<0.05,{ }^{* \star} P<0.01$ and ${ }^{\star \star *} P<0.001$ compared with media-treated DCs. 
DCs a dose-dependent manner. (Figure 1C and Supplemental Figure 2). Consistent with mRNA levels, TRS significantly enhanced secretion of IL-12p40 and IL-12p70 in a dosedependent manner (Figure 1D).

In general, classical mouse DCs is known to express integrin $\alpha \mathrm{X}$ chain protein $\mathrm{CD} 11 \mathrm{c}$, and they have been identified as plasmacytoid DC (pDC) and conventional DC (cDC). Moreover, $\mathrm{cDC}$ can be further divided into the related lymphoid resident $\mathrm{CD} 8^{+} \mathrm{XCR} 1^{+} \mathrm{DC}(\mathrm{cDC} 1)$ and $\mathrm{CD} 8^{-} \mathrm{CD} 103^{+}$ DC (cDC2) $(29,30)$. According to recently reported papers, BMDCs are generated by two strategies using GM-CSF or Flt3L and they constituted of distinctly different DC subsets. Flt3L-derived DC is defined as a steady state DC, which contains pDC and two cDC subsets. However, GM-CSFderived DC is defined as an inflammatory DC and does not include the $\mathrm{CDC} 1(31,32)$. Therefore, we confirmed the effect of TRS on DC maturation by using BMDCs generated through Flt3L treatment. As shown, TRS significantly increased the expression of MHCII and co-stimulatory molecules, including CD40, CD80 and CD86, on Flt3L-derived DCs in a dosedependent manner (Supplemental Figure 3A, B). In addition, TRS significantly increased the secretion levels of IL-12p40 in a dose-dependent manner (Supplemental Figure 3C). Taken together, these results indicate that TRS promoted the maturation and activation of both GM-CSF-derived DCs and Flt3L-derived DCs.

\section{The MAPK and NF- $\kappa B$ Signaling Pathways Were Involved in TRS-Induced Activation of DCs}

The observation that TRS-treated DCs induced the maturation and production of IL-12 led us to investigate the underlying immune signaling pathways. The NF- $\mathrm{KB}$ and MAPK signaling pathways are known to play an essential role in DC maturation and cytokine production. As shown in Figure 2A, TRS-treated DCs exhibit the degradation of $\mathrm{I} \kappa \mathrm{B} \alpha$ and $\mathrm{I} \kappa \mathrm{B} \beta$ proteins in a time-dependent manner. In addition, the nuclear translocation of NF- $\mathrm{KB}$ p 65 following TRS treatment was detected via immunofluorescence (Figure 2B). To gain further insights into TRS-induced signaling, we determined the phosphorylation of c-Jun N-terminal kinase (JNK), p38, and extracellular-signalregulated kinase (ERK) in TRS-treated DCs. TRS induced the phosphorylation of JNK, p38, and ERK in a time-dependent manner (Figure 2C). Furthermore, to determine the relationship between NF- $\kappa \mathrm{B}$ and MAPKs, we investigated the potential effect of TRS-induced NF- $\kappa \mathrm{B}$ activation of DCs in the presence of JNK, p38 and ERK inhibitors. The treatment with MAPK inhibitors significantly decreased the degradation of $I \kappa B \alpha$ and $I \kappa B \beta$ proteins and reduced the phosphorylation of NF- $\kappa B$ p 65 in TRS-treated DCs (Figure 2D and Supplemental Figure 4), suggesting that MAPKs were involved in the upstream signaling required for TRS-induced NF- $\kappa B$ activation. TRSmediated IL-12 production was abolished by treatment of DCs
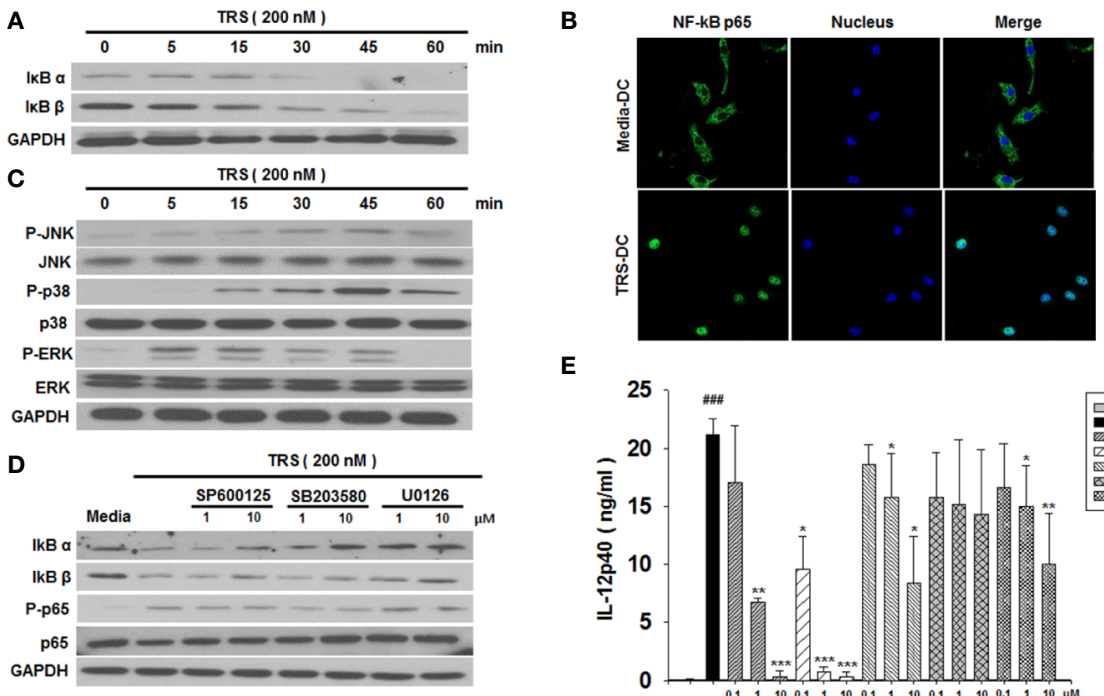

E

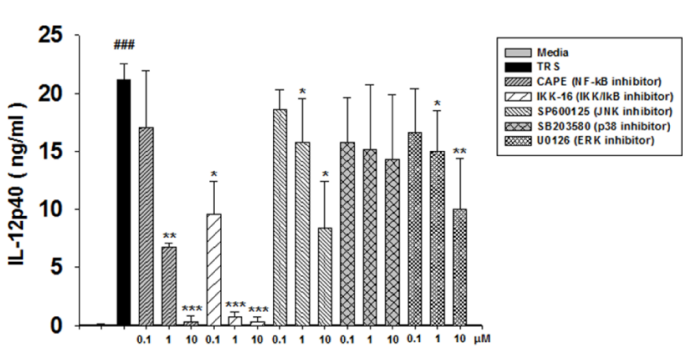

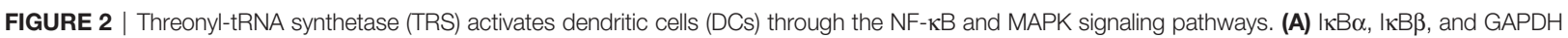
expression levels, as measured by western blotting of DCs treated with TRS in a time-dependent manner (0-60 min). (B) The nuclear translocation of NF- $\mathrm{KB}$ p65, as detected by confocal laser scanning microscopy (LSM 800, Carl Zeiss, Oberkochen, Germany) of DCs treated with TRS (200 nM) for $1 \mathrm{~h}$ and then incubated with an anti-NF-kB p65 antibody (Ab), followed by staining with an Alexa Fluor 488-conjugated Ab and 4',6-diamidino-2-phenylindole (DAPI). (C) DC culture method

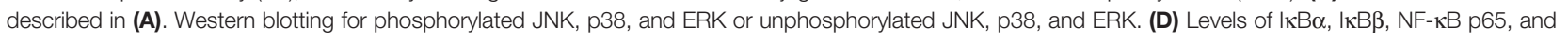
phosphorylated NF- $\mathrm{KB}$ p65, as detected via western blot analysis of DCs pretreated with the MAPK inhibitors (1, $10 \mu \mathrm{M})$ and treated for 30 min with TRS. (E) IL$12 \mathrm{p} 40$ levels in the supernatant, as detected via ELISA of DCs pretreated with the indicated inhibitors $(0.1,1,10 \mu \mathrm{M})$ for $30 \mathrm{~min}$ and treated with TRS for $20 \mathrm{~h}$. The media-treated DCs without inhibitors was analyzed as a control. Experiments were conducted three times independently and are represented as the mean \pm SEM of results performed in triplicate $(n=3)$. Statistical significance was assessed using unpaired Student's $t$-test; ${ }^{\# \# \# ~} P<0.001$ compared with media-treated DCs, ${ }^{\star} P<0.05,{ }^{\star \star} P<0.01$ and ${ }^{\star \star \star} P<0.001$ as determined by one-way analysis of variance with a Bonferroni post-test for multiple comparisons. 


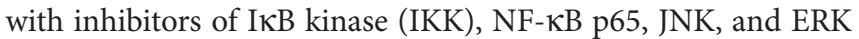
in a dose-dependent manner. In contrast, the p38 kinase inhibitor had no effect (Figure 2E). Taken together, our results indicated that TRS induced the maturation and activation of DCs through the MAPK/NF- $\kappa B$ pathways.

The initiation of biological responses by signaling molecules, including endogenous proteins and hormones is induced by their interaction with cell surface molecules. To investigate whether TRS could attach to the surface of DCs, DCs were incubated with TRS and the localization of TRS was observed by immunofluorescence. TRS was observed to localize on the surface of DCs (Supplemental Figure 5).

\section{TRS Enhanced Th1 Responses via DC- Derived IL-12}

Mature DCs are able to induce the polarization of $\mathrm{CD} 4^{+} \mathrm{T}$ cells into subsets, including Th1, Th2, Th17, and $\mathrm{T}_{\text {reg }}$ cells, depending on the cytokines they produce. We demonstrated that TRS significantly increased the production of IL-12, a strong Th1polarizing cytokine. Therefore, to investigate whether TRSstimulated DCs polarized naïve $\mathrm{CD}^{+} \mathrm{T}$ cells into Th1 cells, ovalbumin (OVA)-pulsed DCs were treated with TRS and then co-cultured with naïve OT-II $\mathrm{CD}^{+}{ }^{+} \mathrm{T}$ cells, followed by the assessment of Th subset populations by cytofluorometric analysis. As shown in Figures 3A, B, TRS-treated DCs significantly increased the percentage of the IFN $-\gamma^{+} \mathrm{CD} 4^{+} \mathrm{T}$ cells (Th1) in a dose-dependent manner. However, TRS- treated DCs did not affect the populations of $\mathrm{IL}-4^{+} \mathrm{CD} 4^{+} \mathrm{T}$ cells (Th2) and FoxP3 ${ }^{+} \mathrm{CD}^{+}{ }^{+} \mathrm{T}$ cells $\left(\mathrm{T}_{\text {reg }}\right)$. TRS-treated DCs was also likely to increase the population of $\mathrm{IL}-17^{+} \mathrm{CD} 4^{+} \mathrm{T}$ cells (Th17), although not statistically significant. TRS-treated DCs significantly increased IFN- $\gamma$ production of co-cultured $\mathrm{CD} 4^{+} \mathrm{T}$ cells in a dose-dependent manner, although TRS partly promoted IL-17 secretion in the co-cultured $\mathrm{CD}^{+}{ }^{+} \mathrm{T}$ cells (Figure 3C). To confirm whether TRS directly affected the polarization of $\mathrm{CD}^{+} \mathrm{T}$ cells without $\mathrm{DCs}$, naïve $\mathrm{CD} 4^{+} \mathrm{T}$ cells were incubated in the presence or absence of TRS under the polarizing conditions of each Th subset, and the levels of each Th subset population were assessed. TRS did not directly affect the polarization of $\mathrm{CD}^{+} \mathrm{T}$ cells (Supplemental Figure 6).

Th1 cell polarization and IFN- $\gamma$ production in $\mathrm{CD} 4^{+}$cells are known to correlate with IL-12, a Th1-polarizing cytokine. To investigate whether IL-12 secretion from TRS-stimulated DCs was related to the increased Th1 cell population and IFN- $\gamma$ production, neutralizing anti-IL-12 monoclonal antibodies (mAbs) were added to the co-cultures of TRS-stimulated DCs and $\mathrm{CD}^{+} \mathrm{T}$ cells, and the levels of Th1 cell populations and IFN- $\gamma$ production were assessed. The addition of anti-IL-12neutralizing mAbs significantly decreased the polarization of $\mathrm{CD}^{+}{ }^{+} \mathrm{IFN}-\gamma^{+}$cells (Figures $3 \mathrm{D}, \mathbf{E}$ ), as well as IFN- $\gamma$ production from $\mathrm{CD}^{+} \mathrm{T}$ cells (Figure 3F). However, the IgG isotype control antibody had no effect on the Th1 response. Taken together, these results showed that TRS induced the polarization of naïve $\mathrm{CD}^{+} \mathrm{T}$ cells into Th1 cells via DC-derived IL-12.

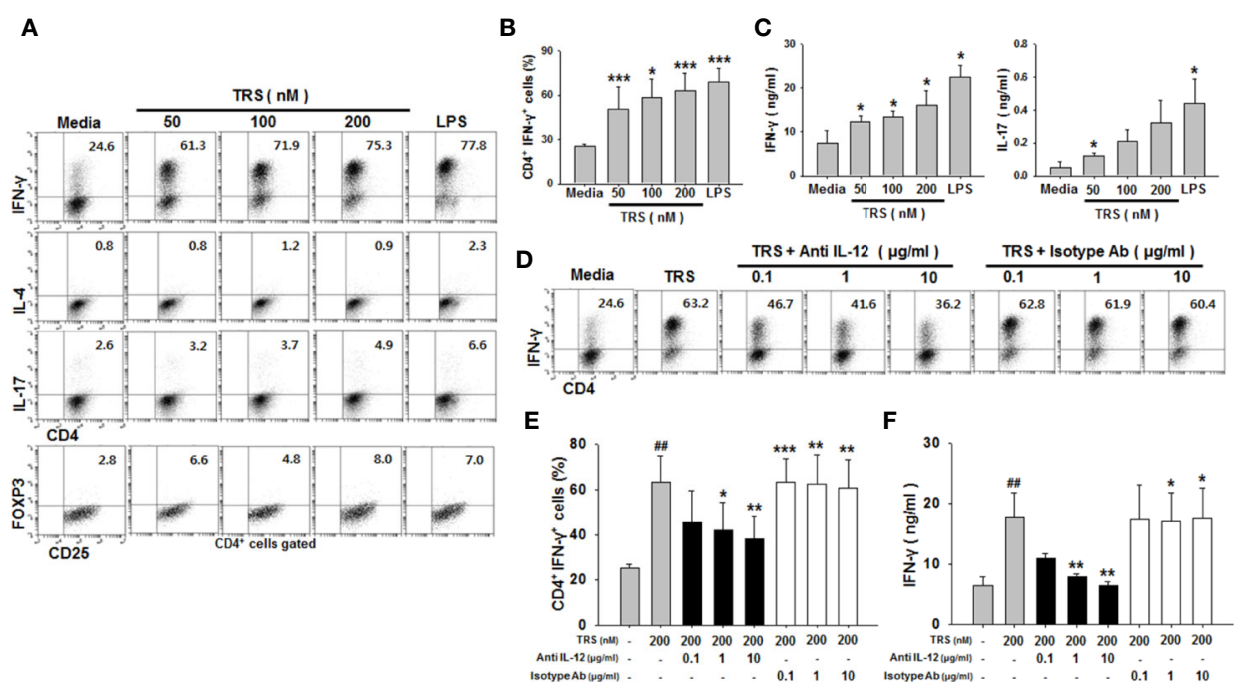

FIGURE 3 | Threonyl-tRNA synthetase (TRS) induces the polarization of Th1 cells through the secretion of IL-12 from DCs. Dendritic cells (DCs) were treated with ovalbumin (OVA, $10 \mu \mathrm{g} / \mathrm{ml}$ ) for $2 \mathrm{~h}$ and OVA-DCs were treated with TRS (50, 100, and $200 \mathrm{nM}$ ) or LPS (500 ng/ml) for 6 h. DCs were cultured with OT-II CD4+ T cells at a 1:10 ratio for three days. (A) IFN- $\gamma_{-}, \mathrm{IL}-4-$, IL-17- and Foxp3-expressing CD4 ${ }^{+} \mathrm{T}$ cell populations, as analyzed by flow cytometry. Representative figures are presented. (B) The data are expressed as the mean \pm SD of three independent experiments $(n=3)$. (C) Protein levels of IFN- $\gamma$ and IL-17 in the supernatant, as analyzed using ELISA. Data shown represent the mean \pm SEM of three independent experiments $(n=3)$. (B, C) ${ }^{\star} P<0.05$, and ${ }^{\star \star *} P<0.001$ compared with mediatreated DCs. (D) IFN- $\gamma^{+}$CD4 ${ }^{+} \mathrm{T}$ cells, as analyzed via flow cytometry, of DCs treated with OVA (10 $\left.\mu \mathrm{g} / \mathrm{ml}\right)$ for $2 \mathrm{~h}$ and then treated with $200 \mathrm{nM}$ TRS for $6 \mathrm{~h}$. The DCs were cultured with OT-II CD4 ${ }^{+} \mathrm{T}$ cells at a 1:10 ratio in the presence of anti-IL-12 antibody (Ab) $(0.1-1 \mu \mathrm{g} / \mathrm{ml})$ or isotype Ab (0.1-1 $\left.\mu \mathrm{g} / \mathrm{ml}\right)$ for three days. Representative figures are presented. (E) The population of IFN $-\gamma^{+} C D 4^{+} T$ cells is presented as the mean \pm SD of three independent experiments ( $\left.n=3\right)$. (F) Protein levels of IFN- $\gamma$ in the supernatants, as detected by ELISA. Data shown represent the mean \pm SEM of three independent experiments $(n=3)$. (E, $\mathbf{F})$ Statistical significance was assessed using unpaired Student's t-test; ${ }^{\# \#} P<0.01$ compared with $\mathrm{CD} 4^{+} \mathrm{T}$ cells co-cultured with media-treated DCs, ${ }^{\star} P<0.05$, ${ }^{\star \star} P<0.01$ and ${ }^{\star \star \star} P<0.001$ as determined by one-way analysis of variance with a Bonferroni post-test for multiple comparisons. 


\section{TRS Stimulated the Maturation of Splenic DCs and TRS-Treated Splenic DCs Induced Th1 Polarization}

We further examined the effect of TRS on DC maturation and the Th1 response using primary splenic DCs. Isolated primary DCs from mouse spleen were used to detect the levels of maturation in the following conditions: media treatment, TRS treatment, and LPS treatment. TRS-treated splenic DCs increased the expression of CD80, CD86, and MHC class II molecules (Figures 4A, B). Consistent with the analysis of BMDCs, secretion of IL- 12 p 40 was promoted by TRS treatment in splenic DCs (Figure 4C). In addition, TRSactivated splenic DCs selectively increased the polarization of IFN- $\gamma^{+} \mathrm{CD} 4^{+} \mathrm{T}$ cells from the OT-II naïve $\mathrm{CD} 4^{+} \mathrm{T}$ cells. IL$17^{+} \mathrm{CD} 4^{+} \mathrm{T}$ cell population also increased, although not statistically significant (Figures 4D, E). These results confirmed that TRS induced the maturation of not only bone marrow-derived DCs, but also that of primary splenic DCs.

\section{TRS-Treated DCs Induced a Th1 Response In Vivo}

To confirm the in vivo relevance of our observations, OVApulsed, TRS-treated DCs were adoptively transferred to OT-II mice. Seven days later, Th1, Th2 and Th17 cytokine profiles were measured in the presence of OVA in the draining lymph nodes of
DC-immunized mice. Consistent with the results from in vitro co-cultures, immunization of mice with TRS-stimulated DCs significantly upregulated the populations of IFN $-\gamma^{+} \mathrm{CD} 4^{+} \mathrm{T}$ cells and $\mathrm{IL}-17^{+} \mathrm{CD} 4^{+} \mathrm{T}$ cells, compared with the media-treated-DCimmunized mice. The population of IL $-4^{+} \mathrm{CD} 4^{+} \mathrm{T}$ cells showed similar levels in both media-treated DC- and TRS-treated DCimmunized mice (Figures 5A, B). Furthermore, immunization of mice with TRS-stimulated DCs significantly increased IFN- $\gamma$ production. However, levels of IL-4 exhibited no differences in both the media-treated DC and TRS-treated DC groups. The secretion of IL-17 was likely to show an increased pattern by TRS-stimulated DCs, but has no statistical significance (Figure 5C). These results demonstrated that TRS significantly enhanced a Th1 response in vivo.

\section{TRS-Treated DCs Showed an Increased Anti-Viral Effect Against IAV In Vivo}

IFN- $\gamma$ is a type II interferon and has been reported to have an anti-viral effect similar to that of type I interferon (19), and it is known that the increase in the population of antigen (Ag)specific Th1 cells affects the $\mathrm{CD}^{+} \mathrm{T}$ cell population (3). To investigate whether the TRS-DC-mediated-Th1 response had an anti-IAV effect, hemagglutinin (HA)-pulsed, TRS-DCs were used to immunize mice. HA is a well-known model Ag of IAV and has been used to stimulate an IAV-specific immune response
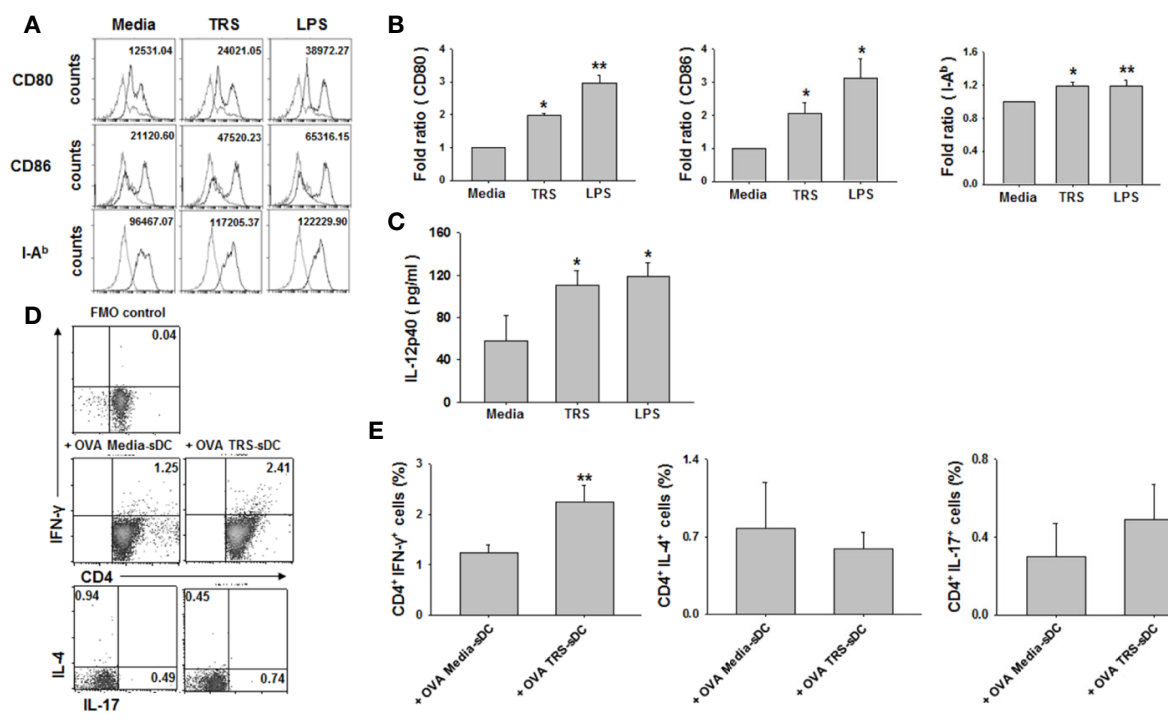

\section{(1)}
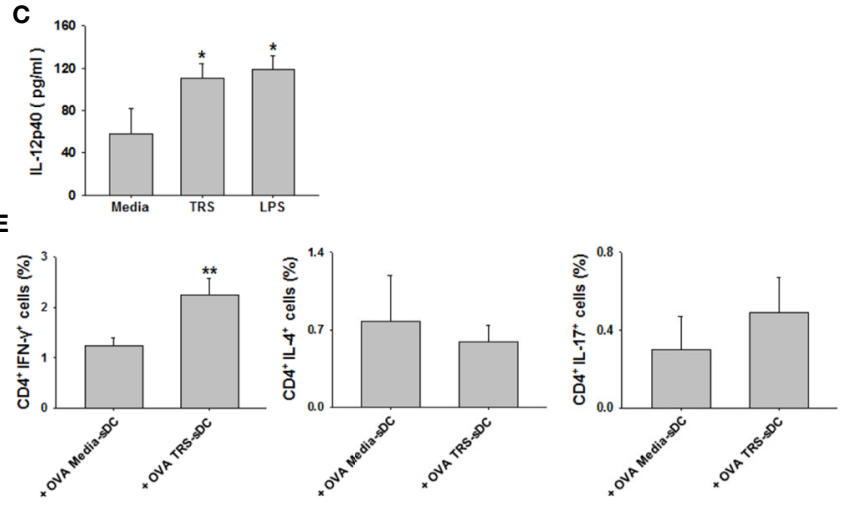

FIGURE 4 | Threonyl-tRNA synthetase (TRS) induces the maturation of primary splenic DCs and promotes the polarization of Th1 cells. Splenic dendritic cells (DCs) were isolated from mouse spleen using CD11c MicroBeads (Miltenyi Biotec) and primary splenic DCs were cultured for $20 \mathrm{~h}$ with TRS (200 nM) or LPS (500 ng/ml). (A) The expression of CD80, CD86, and I-A molecules, as detected by flow cytometry for CD11 ${ }^{+}$gated cells. Gray histograms, isotype control; black histograms, anti-CD80, anti-CD86, and anti-I-A $\mathrm{Ab}$. Representative figures are presented. The value shown in the histograms represents the mean fluorescence intensity. (B) The fold ratio of surface molecules expression was plotted with the media-treated DCs as 1.0. The data represent mean \pm SD of three independent experiments ( $\mathrm{n}=3$ ); ${ }^{\star} P<0.05$ and ${ }^{\star \star} P<0.01$ compared with media-treated DCs. (C) Levels of IL-12p40 in cell supernatants, as detected by enzyme-linked immunosorbent assay (ELISA). Experiments were conducted three times independently and are represented as the mean \pm SEM ( $n=3$ ). Statistical significance was assessed using unpaired Student's $t$-test; ${ }^{\star} P<0.05$ compared with media-treated DCs. (D) IFN- $\boldsymbol{\gamma}^{-}$, IL-4-, and IL-17-expressing cells, as detected by flow cytometry for CD4 ${ }^{+}$gated cells of splenic DCs treated with OVA $(10 \mu \mathrm{g} / \mathrm{ml})$ for $2 \mathrm{~h}$ and then treated with media or TRS $(200 \mathrm{nM})$ for $6 \mathrm{~h}$. The DCs were cultured with OT-II CD4 ${ }^{+}$T cells at a $1: 5$ ratio for three days. Some cells were only stained with CD4 to generate FMO control for IFN- $\gamma$. Representative figures are presented. (E) The populations of $\mathrm{CD} 4^{+}-\mathrm{IFN}-\gamma^{+},-\mathrm{IL}-4^{+}$, and $-\mathrm{IL}-17^{+}$cells are presented as the mean $\pm \mathrm{SD}$ of three independent experiments $(\mathrm{n}=3) .{ }^{*} P<0.05$ and ${ }^{\star \star} P<0.01$ compared with the group injected with OVA, media-treated DCs. 
(33, 34). Recombinant HA protein had no effect on DC maturation and activation (data not shown). As shown in Figure 6A, TRS-DC-immunized mice exhibit a higher survival ratio and body weight compared with media-treated DCimmunized mice. Moreover, TRS-DC-immunized mice significantly induced IAV clearance in lungs compared with the media-treated DC-immunized mice (Figure 6B). The populations of IFN $-\gamma^{+} \mathrm{CD} 4^{+} \mathrm{T}$ cells and IFN $-\gamma^{+} \mathrm{CD} 8^{+} \mathrm{T}$ cells were significantly upregulated in bronchoalveolar lavage fluid (BALF) of TRS-DC-immunized mice (Figure 6C). In addition, IFN- $\boldsymbol{\gamma}$ levels were higher in the lungs of TRS-DC-immunized mice, compared to those in the media-treated DC-immunized mice (Figure 6D). Taken together, these data revealed that TRS had an anti-IAV effect through the DC-mediated increase in IFN- $\gamma$-secreting $\mathrm{CD}^{+}$and $-\mathrm{CD}^{+} \mathrm{T}$ cell populations.

\section{DISCUSSION}

The aaRSs, secreted from several different types of cells, including cancer and immune cells, have a variety of extracellular functions $(5,13,35-37)$. TRS, a class II aaRS, is secreted into the extracellular space upon exposure to TNF- $\alpha$ or VEGF from vascular endothelial cells (13). As TRS is also found in the sera of autoimmune patients, it is of interest to investigate its non-translation functions, especially, its cytokine-like activity in the regulation of inflammatory responses and the immune modulatory functions of DCs, which shape Ag-specific T cell immunity. In the present study, the data suggested that TRS was a novel effector that promoted the phenotypic and functional maturation and activation of DCs. TRS significantly upregulated the expression levels of costimulatory and MHC class II molecules on DCs. In addition, TRS increased the production of pro-inflammatory cytokines including IL-12 in DCs. Moreover, the IL-12 secreted from TRS-stimulated DCs triggered the polarization of $\mathrm{CD}^{+} \mathrm{T}$ cells to a Th1 subset. This is the first study to demonstrate that TRS may exhibit cytokinelike functions to induce the maturation and activation of DCs, and also to promote a Th1 response in a DC-dependent manner. This finding may also explain the role of TRS in autoimmune diseases and angiogenesis associated with the Th1 subset and IFN- $\gamma$.

Most of our in vitro experiments were conducted using bone marrow-derived DCs, which is an inflammation-specific DC. It is unclear whether these results are similar in different types of DCs, such as monocyte-derived DCs and tissue-resident DCs. In this study, we also included primary splenic DCs to confirm the TRS-induced DC-activation and Th1 polarization. As monocytederived DCs and tissue-resident DCs, including splenic DCs, are major populations in the total DC population (29-32), we expect that TRS is an effective molecule for DC activation and maturation.

TRS-mediated induction of Th1 response may occur through DC-derived IL-12. IL-12 is an important cytokine for the polarization of IFN- $\gamma$-secreting $\mathrm{CD}^{+} \mathrm{T}$ cells (15). TRS-treated
A
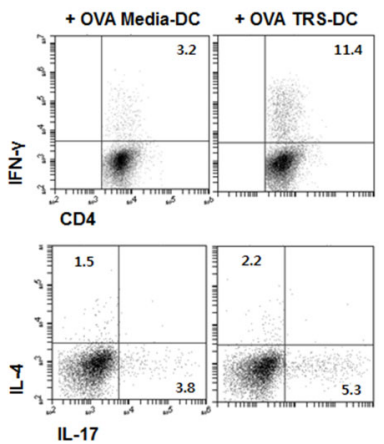

B

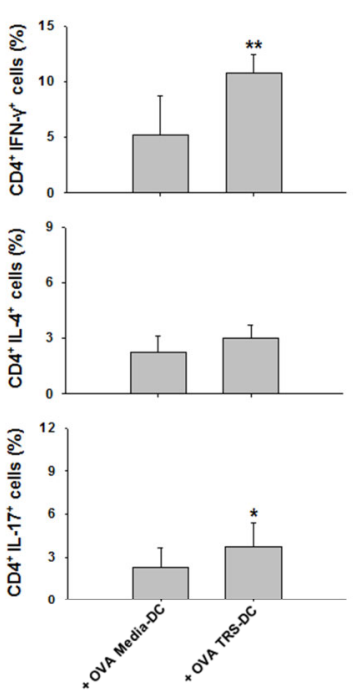

C

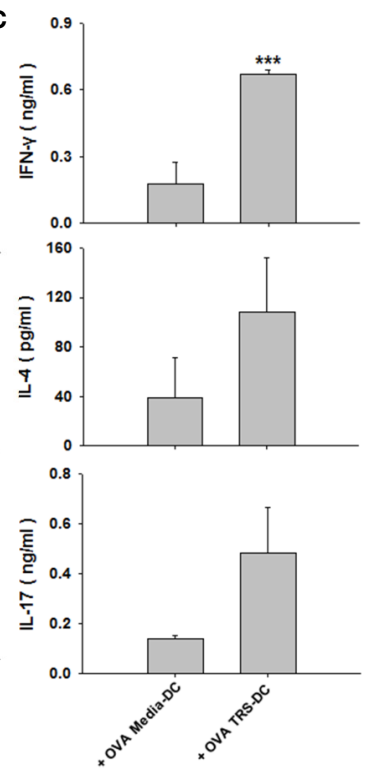

FIGURE 5 | Threonyl-tRNA synthetase (TRS)-treated DCs induce Th1 polarization in vivo. Dendritic cells (DCs) were isolated from C57BL/6 mice as described in the Materials and Methods. Immature-DCs (iDCs) were cultured with ovalbumin (OVA, $10 \mu \mathrm{g} / \mathrm{ml}$ ) for $2 \mathrm{~h}$ and OVA-DCs were treated with media or TRS (200 nM) for $6 \mathrm{~h}$, harvested, and then, DCs were subcutaneously injected into OT-II mice through the footpad. After seven days, the draining lymph node cells were isolated and cultured for three days in the presence with OVA $(100 \mu \mathrm{g} / \mathrm{ml})$. (A) The populations of IFN- $\gamma_{-}$, IL-4-, and IL-17-expressing CD4 ${ }^{+} \mathrm{T}$ cells, as analyzed by flow cytometry. Representative figures are presented. Results from (A) are summarized in (B) as the mean \pm SD of three independent experiments $(n=6)$. (C) Protein levels of IFN- $\gamma$, IL-4, and IL-17 in the culture supernatant, as analyzed using enzyme-linked immunosorbent assay. Data shown represent the mean \pm SEM of three independent experiments $(\mathrm{n}=6)$. $(\mathbf{B}, \mathbf{C}){ }^{\star} P<0.05,{ }^{\star \star} P<0.01,{ }^{\# \#} P<0.01$, and ${ }^{\star \star *} P<0.001$ compared with the group injected with OVA, media-treated DCs. 
DCs upregulated the secretion of IL-12 and increased the population of IFN- $\gamma$-secreting $\mathrm{CD}^{+} \mathrm{T}$ cells in co-cultures of DCs and $\mathrm{CD} 4^{+} \mathrm{T}$ cells. The addition of a neutralizing anti-IL-12 $\mathrm{mAb}$ to the co-culture system significantly suppressed the population of IFN- $\gamma$-secreting $\mathrm{CD}^{+} \mathrm{T}$ cells and IFN- $\gamma$ secretion. In the co-cultured of TRS-DCs and $\mathrm{CD}^{+}{ }^{+} \mathrm{T}$ cells in the presence of anti-IL-12 Ab, we confirmed that IL-12 was neutralized by the anti-IL-12 $\mathrm{Ab}$ addition in a dose-dependent manner. (Supplemental Figure 7A), clearly indicating that the Th1 polarization in the co-culture system was mainly due to the secreted IL-12 from TRS-DCs. Furthermore, in addition to IL12 , other factors may be additionally involved in the Th1 responses increased by TRS-DCs. The anti-IL-12 mAb addition did not completely neutralize the Th1 responses induced by TRSDCs, although it decreased the levels of Th1 responses (IFN- $\gamma$ secreting $\mathrm{CD}^{+} \mathrm{T}$ cell population and IFN- $\gamma$ secretion) to the basal levels, similar to those in the co-culture of media-DCs and CD4 T cells. TRS treatment increased co-stimulatory molecules (CD40, CD80, and CD86, Figures 1A, B) and Th1-related cytokines in DCs (IL-1 $\beta$, IL- 6 and TNF- $\alpha$, Figure 1C and Supplement Figure. 2).

Moreover, injection of OT-II mice with TRS-treated, OVApulsed DCs increased the OVA-specific Th1 cell population. In contrast, TRS did not affect the polarization of other $\mathrm{CD} 4^{+} \mathrm{T}$ cell subsets, such as Th2, Th17, and $\mathrm{T}_{\text {reg }}$ cells in co-cultures of DCs and $\mathrm{CD}^{+}{ }^{+} \mathrm{T}$ cells (Figure 3). Furthermore, TRS did not directly induce $\mathrm{CD}^{+} \mathrm{T}$ cell polarization in the presence of $\mathrm{CD} 3$ and CD28 stimuli (Supplemental Figure 6), indicating that TRS increased Th1 responses via IL-12 secreted from DCs matured and activated by TRS treatment.

TRS-treated DCs partially increased the secretion of IL-17 (Figures 3C and 4D, E) and population of IL-17+ CD4+ cells in the co-culture system and in vivo experiments (Figures $5 \mathbf{A}, \mathbf{B}$ ), although the increased levels were not statistically significant. Therefore, it is likely that TRS partially affected the polarization of Th17 cells and IL-17 secreted from Th17 cell. In addition, Th1 cell population may be a source of the increased IL-17 as Th1 cells are reported to secrete IL-17 in a pro-inflammatory environment (Supplemental Figure 7B) (38). Further research is needed to investigate the direct effect of TRS on Th17 responses and any contribution of Th17 cells in Th1 responses.

TRS-mediated induction of IL-12 production in DCs may occur via NF- $\kappa \mathrm{B}$ activation through MAPK signaling, involving the upstream molecules of NF- $\mathrm{KB}$. DC maturation via the MAPK and NF- $\kappa \mathrm{B}$ signaling pathways is well known (34-41). MAPK and $\mathrm{NF}-\kappa \mathrm{B}$ are conserved signaling components that play essential roles in both innate and adaptive immune responses. Three major molecules involved in MAPK signaling are: ERK, p38 MAP kinase, and JNK (40). Moreover, the intracellular signaling pathways, including $\mathrm{NF}-\kappa \mathrm{B}$, are associated with the
A

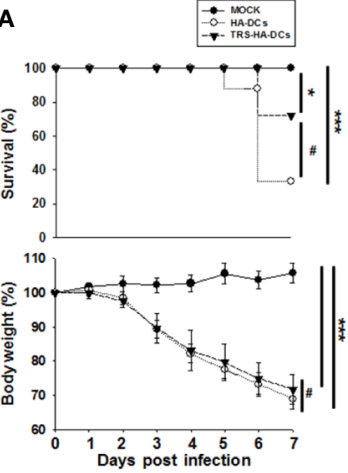

D

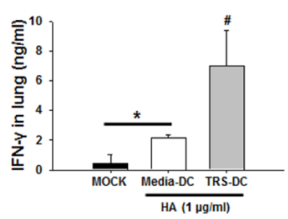

B
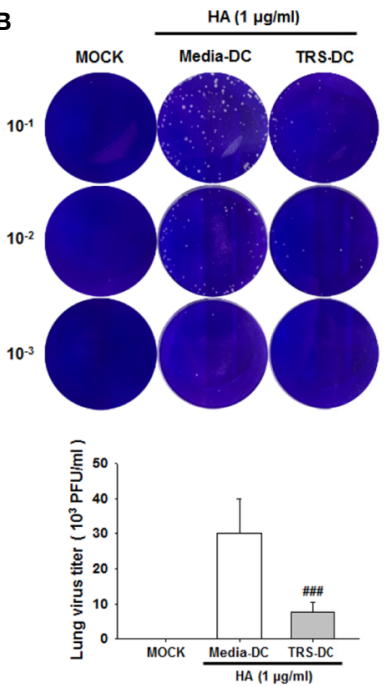

C
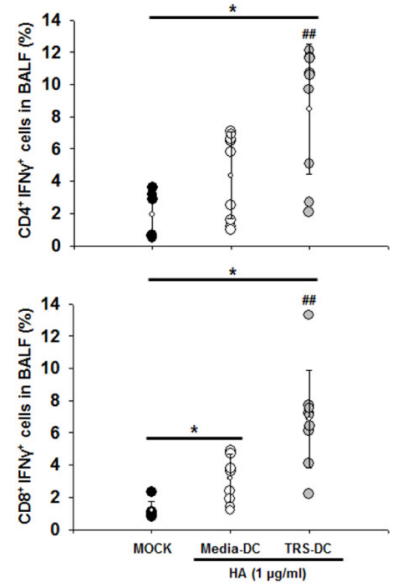

FIGURE 6 | Threonyl-tRNA synthetase (TRS)-treated DCs induce an anti-viral effect in influenza virus AWSN/1933 (H1N1)-infected mice. Female 7-week-old C57BL/6 mice were immunized with hemagglutinin (HA)- or TRS-HA-DCs. Three days later, mice were infected intranasally with 1 mLD 50 of H1N1 influenza. (A) After infection for 7 days, infected mice were monitored for body weight loss and survival. Data represent $n=12$ mice (MOCK), $n=18$ mice (HA-DC), and $n=18$ mice (TRSHA-DC) from three independent experiments. Data shown are the mean \pm SD and statistical significance was analyzed using Kaplan-Meier method and a log-rank test (survival) and Mann-Whitney $U$ test (body weight); ${ }^{\star} P<0.05$, and ${ }^{* \star *} P<0.001$ compared with the group injected with PBS-injected groups (MOCK), ${ }^{*} P<0.05$ compared with HA-DCs-injected groups. (B) Plaque assays of live influenza from whole lung at 7 days after infection. (C) Quantification of IFN- $\gamma^{+} \mathrm{CD} 4^{+} \mathrm{T}$ cells and IFN- $\gamma^{+} C D 8^{+} T$ cells identified in the bronchoalveolar lavage fluid by flow cytometry. Data represent $n=6$ mice (MOCK), $n=9$ mice (HA-DC), and $n=9$ mice (TRS-HADC) from three independent experiments. (D) Protein levels of IFN- $\gamma$ in the lung, as detected by ELISA Data shown represent the mean \pm SEM of results performed in triplicate. Data shown are the mean \pm SD (B, C), \pm SEM (D) and statistical significance was assessed using unpaired Student's $t$-test; ${ }^{\star} P<0.05$ compared with

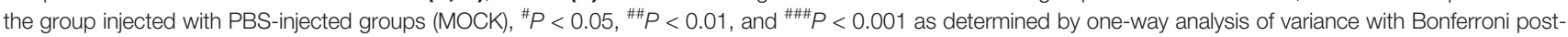
test for multiple comparisons. 
regulation of pro-inflammatory cytokines following the stimulation of macrophages and DCs $(41,42)$. We have shown that TRS significantly induced the maturation of DCs through phosphorylation of JNK, and ERK, and activation of the NF- $\mathrm{KB}$ pathways. In addition, we confirmed decreased IL-12 secretion following treatment with JNK and ERK inhibitors. Although the p38 inhibitor suppressed the activation of NF-kB signaling pathways in the TRS-treated DCs, it failed to block the secretion of IL-12p40. Consequently, TRS induced DC maturation and secretion of IL-12 via the ERK/JNK-mediated NF- $\kappa \mathrm{B}$ pathways.

Exogenous molecules that cannot pass through the cell membrane must directly interact with the cell surface in order to induce the biological functions of target cells. Although a receptor for TRS has not been reported, our data raises the question that TRS is probably related to the surface of DC and could initiate a signaling cascade for DC maturation and activation. We confirmed the localization of TRS on the surface of DCs by immunofluorescent microscopic analysis, although not sufficient to prove the direct interaction (Supplemental Figure 5). Cell surface receptors for other aaRSs have been reported, although further studies are needed to define a receptor of TRS on APCs, as well as the effect of TRS on other APCs. Lysyl-tRNA synthetase (KRS) interacts with the $67-\mathrm{kDa}$ laminin receptor (67LR), leading to cancer cell migration during metastasis $(43,44)$.

IFN- $\gamma$ is an anti-viral cytokine, although relatively weak compared with IFN- $\alpha$ or IFN- $\beta(18,19,24,25)$. In addition, DCs are important sensors to detect viral products and alert the immune system to the presence of virus $(45,46)$. We demonstrated that TRS increased IFN- $\gamma$ secretion through a DC-mediated Th1 response. Therefore, we conducted experiments to confirm the anti-viral effect of TRS in mice infected with IAV. HA-pulsed, TRS-treated DCs, instead of the whole TRS protein, were used for immunization to exclude the effects of natural killer cells or other APCs, including macrophages and B cells. In addition, $\mathrm{HA}$ is well-known as a surface Ag of A/WSN/1933 (H1N1) influenza virus and is used for Ag-specific immune responses $(33,34)$. HA itself, did not affect the activation and maturation of DCs (data not shown). Adoptive transfer of HA-pulsed, TRS-treated DCs significantly increased the populations of IFN $-\gamma^{+} \mathrm{CD} 4^{+} \mathrm{T}$ cells and IFN$\gamma^{+} \mathrm{CD}^{+} \mathrm{T}$ cells in the BALF and decreased the number of live influenza particles in the lung, resulting in an increased survival period and bodyweight of influenza-infected mice.

In addition, we investigated the effects of various recombinant aa-tRNA synthetases and their complexed components (AIMP2, DRS, HRS, LRS, TRS, KRS, and YRS) on DC, and only KRS and TRS induced maturation and activation of DCs with different extents (data not shown). Although TRS and KRS are categorized into the same group in aaRS classification, this is just a functional classification. In addition, TRS and KRS induced DC maturation through distinctly different pathways ERK phosphorylation is a representative difference occurring only in TRS-, not KRSinduced DC maturation.
In summary, we demonstrated that TRS enhanced a Th1 response through the maturation and activation of DCs with Th1-polarizing ability, which was mainly due to the increased IL12 production by the MAPK/NF- $\kappa \mathrm{B}$ pathways. These data may explain the presence of autoantibodies in patients with autoimmune diseases, and also suggest TRS as a novel candidate for a protective adjuvant against respiratory viruses, including IAV.

\section{DATA AVAILABILITY STATEMENT}

The raw data supporting the conclusions of this article will be made available by the authors, without undue reservation.

\section{ETHICS STATEMENT}

The animal study was reviewed and approved by Institutional Animal Care and Use Committee of Korea University.

\section{AUTHOR CONTRIBUTIONS}

$\mathrm{H}-\mathrm{JJ}$ designed and performed all the experiments. H-JJ, S-HP, K-MC, DC, and TK analyzed and interpreted the experimental results. KIJ provided the IAV and protocol for influenza infection in mouse model. DC contributed reagents/materials. $\mathrm{H}-\mathrm{JJ}$ and TK collaborated on manuscript writing. TK supervised the study and corrected the manuscript. All authors contributed to the article and approved the submitted version.

\section{FUNDING}

This work was supported by the National Research Foundation of Korea (NRF) grant (NRF-2017R1A2B2009442) and the Korea University grant.

\section{ACKNOWLEDGMENTS}

We thank Si Hoon Park (Korea University, Korea) for providing valuable discussion and technical assistance. We also thank to support by a Korea University Grant.

\section{SUPPLEMENTARY MATERIAL}

The Supplementary Material for this article can be found online at: https://www.frontiersin.org/articles/10.3389/fimmu.2020. 571959/full\#supplementary-material 


\section{REFERENCES}

1. Son SH, Park MC, Kim S. Extracellular activities of aminoacyl-tRNA synthetases: new mediators for cell-cell communication. Top Curr Chem (2014) 344:145-66. doi: 10.1007/128_2013_476

2. Martinis SA, Plateau P, Cavarelli J, Florentz C. Aminoacyl-tRNA synthetases: a family of expanding functions. Mittelwihr, France, October 10-15, 1999. EMBO J (1999) 18(17):4591-6. doi: 10.1093/emboj/18.17.4591

3. Liang D, Tian L, You R, Halpert MM, Konduri V, Baig YC, et al. AIMp1 Potentiates TH1 Polarization and Is Critical for Effective Antitumor and Antiviral Immunity. Front Immunol (2017) 8:1801. doi: 10.3389/fimmu. 2017.01801

4. Lee EY, Lee HC, Kim HK, Jang SY, Park SJ, Kim YH, et al. Infection-specific phosphorylation of glutamyl-prolyl tRNA synthetase induces antiviral immunity. Nat Immunol (2016) 17(11):1252-62. doi: 10.1038/ni.3542

5. Park MC, Kang T, Jin D, Han JM, Kim SB, Park YJ, et al. Secreted human glycyl-tRNA synthetase implicated in defense against ERK-activated tumorigenesis. Proc Natl Acad Sci USA (2012) 109(11):E640-647. doi: 10.1073/pnas.1200194109

6. Kim MS, Song JH, Cohen EP, Cho D, Kim TS. Aminoacyl tRNA SynthetaseInteracting Multifunctional Protein 1 Activates NK Cells via Macrophages In Vitro and In Vivo. J Immunol (2017) 198(10):4140-7. doi: 10.4049/ jimmunol.1601558

7. Kim MS, Kim TS. Aminoacyl tRNA Synthetase-Interacting Multifunctional Protein 1 Acts as a Novel B Cell-Activating Factor In Vitro and In Vivo. J Immunol (2015) 194(10):4729-36. doi: 10.4049/jimmunol.1401352

8. Kim MS, Lee A, Cho D, Kim TS. AIMP1 regulates TCR signaling and induces differentiation of regulatory $\mathrm{T}$ cells by interfering with lipid raft association. Biochem Biophys Res Commun (2019) 514(3):875-80. doi: 10.1016/ j.bbrc.2019.05.040

9. Lim HX, Jung HJ, Lee A, Park SH, Han BW, Cho D, et al. Lysyl-Transfer RNA Synthetase Induces the Maturation of Dendritic Cells through MAPK and NF-kappaB Pathways, Strongly Contributing to Enhanced Th1 Cell Responses. J Immunol (2018) 201(9):2832-41. doi: 10.4049/jimmunol. 1800386

10. Kim E, Kim SH, Kim S, Cho D, Kim TS. AIMP1/p43 protein induces the maturation of bone marrow-derived dendritic cells with $\mathrm{T}$ helper type 1polarizing ability. J Immunol (2008) 180(5):2894-902. doi: 10.4049/ jimmunol.180.5.2894

11. Cojocaru M, Cojocaru IM, Chicos B. New Insights into Antisynthetase Syndrome. Maedica (Buchar) (2016) 11(2):130-5.

12. Labirua A, Lundberg IE. Interstitial lung disease and idiopathic inflammatory myopathies: progress and pitfalls. Curr Opin Rheumatol (2010) 22(6):633-8. doi: 10.1097/BOR.0b013e32833f1970

13. Williams TF, Mirando AC, Wilkinson B, Francklyn CS, Lounsbury KM. Secreted Threonyl-tRNA synthetase stimulates endothelial cell migration and angiogenesis. Sci Rep (2013) 3:1317. doi: 10.1038/srep01317

14. Jeong SJ, Kim JH, Lim BJ, Yoon I, Song JA, Moon HS, et al. Inhibition of MUC1 biosynthesis via threonyl-tRNA synthetase suppresses pancreatic cancer cell migration. Exp Mol Med (2018) 50(1):e424. doi: 10.1038/ emm. 2017.231

15. Zhu J, Yamane H, Paul WE. Differentiation of effector CD4 T cell populations ${ }^{*}$ ). Annu Rev Immunol (2010) 28:445-89. doi: 10.1146/annurev-immunol030409-101212

16. Gutcher I, Becher B. APC-derived cytokines and T cell polarization in autoimmune inflammation. J Clin Invest (2007) 117(5):1119-27. doi: 10.1172/ JCI31720

17. de Jong EC, Smits HH, Kapsenberg ML. Dendritic cell-mediated T cell polarization. Springer Semin Immunopathol (2005) 26(3):289-307. doi: 10.1007/s00281-004-0167-1

18. Kang S, Brown HM, Hwang S. Direct Antiviral Mechanisms of InterferonGamma. Immune Netw (2018) 18(5):e33. doi: 10.4110/in.2018.18.e33

19. He X-S, Draghi M, Mahmood K, Holmes TH, Kemble GW, Dekker CL, et al. $\mathrm{T}$ cell-dependent production of IFN- $\gamma$ by NK cells in response to influenza A virus. J Clin Invest (2004) 114(12):1812-9. doi: 10.1172/jci22797

20. Smarr CB, Bryce PJ, Miller SD. Antigen-specific tolerance in immunotherapy of Th2-associated allergic diseases. Crit Rev Immunol (2013) 33(5):389-414. doi: $10.1615 /$ critrevimmunol.2013007046
21. Ouyang W, Kolls JK, Zheng Y. The biological functions of T helper 17 cell effector cytokines in inflammation. Immunity (2008) 28(4):454-67. doi: 10.1016/j.immuni.2008.03.004

22. Kondelkova K, Vokurkova D, Krejsek J, Borska L, Fiala Z, Ctirad A. Regulatory T cells (TREG) and their roles in immune system with respect to immunopathological disorders. Acta Med (Hradec Kralove) (2010) 53 (2):73-7. doi: 10.14712/18059694.2016.63

23. Lee AJ, Ashkar AA. The Dual Nature of Type I and Type II Interferons. Front Immunol (2018) 9:2061. doi: 10.3389/fimmu.2018.02061

24. Rhein BA, Powers LS, Rogers K, Anantpadma M, Singh BK, Sakurai Y, et al. Interferon-gamma Inhibits Ebola Virus Infection. PloS Pathog (2015) 11(11): e1005263. doi: 10.1371/journal.ppat.1005263

25. Mao R, Zhang J, Jiang D, Cai D, Levy JM, Cuconati A, et al. Indoleamine 2,3dioxygenase mediates the antiviral effect of gamma interferon against hepatitis B virus in human hepatocyte-derived cells. J Virol (2011) 85(2):1048-57. doi: 10.1128/JVI.01998-10

26. Prestwood TR, Morar MM, Zellweger RM, Miller R, May MM, Yauch LE, et al. Gamma interferon (IFN-gamma) receptor restricts systemic dengue virus replication and prevents paralysis in IFN-alpha/beta receptor-deficient mice. J Virol (2012) 86(23):12561-70. doi: 10.1128/JVI.06743-11

27. Jung KI, Ko DH, Shin N, Pyo CW, Choi SY. Endoplasmic reticulumassociated degradation potentiates the infectivity of influenza A virus by regulating the host redox state. Free Radic Biol Med (2019) 135:293-305. doi: 10.1016/j.freeradbiomed.2019.03.021

28. Jung KI, Pyo CW, Choi SY. Influenza A virus-induced autophagy contributes to enhancement of virus infectivity by SOD1 downregulation in alveolar epithelial cells. Biochem Biophys Res Commun (2018) 498(4):960-6. doi: 10.1016/j.bbrc.2018.03.089

29. Zhang W, Ding Y, Sun L, Hong Q, Sun Y, Han L, et al. Bone marrow-derived inflammatory and steady state DCs are different in both functions and survival. Cell Immunol (2018) 331:100-9. doi: 10.1016/j.cellimm.2018.06.001

30. Merad M, Sathe P, Helft J, Miller J, Mortha A. The dendritic cell lineage: ontogeny and function of dendritic cells and their subsets in the steady state and the inflamed setting. Annu Rev Immunol (2013) 31:563-604. doi: 10.1146/ annurev-immunol-020711-074950

31. Mayer CT, Ghorbani P, Nandan A, Dudek M, Arnold-Schrauf C, Hesse C, et al. Selective and efficient generation of functional Batf3-dependent CD103+ dendritic cells from mouse bone marrow. Blood (2014) 124(20):3081-91. doi: 10.1182/blood-2013-12-545772

32. Xu Y, Zhan Y, Lew AM, Naik SH, Kershaw MH. Differential development of murine dendritic cells by GM-CSF versus Flt3 ligand has implications for inflammation and trafficking. J Immunol (2007) 179(11):7577-84. doi: 10.4049/jimmunol.179.11.7577

33. Stanekova Z, Vareckova E. Conserved epitopes of influenza A virus inducing protective immunity and their prospects for universal vaccine development. Virol J (2010) 7:351. doi: 10.1186/1743-422x-7-351

34. Guo C, Zhang H, Xie X, Liu Y, Sun L, Li H, et al. H1N1 influenza virus epitopes classified by monoclonal antibodies. Exp Ther Med (2018) 16 (3):2001-7. doi: 10.3892/etm.2018.6429

35. Kim SB, Kim HR, Park MC, Cho S, Goughnour PC, Han D, et al. Caspase-8 controls the secretion of inflammatory lysyl-tRNA synthetase in exosomes from cancer cells. J Cell Biol (2017) 216(7):2201-16. doi: 10.1083/ jcb.201605118

36. Barnett G, Jakobsen AM, Tas M, Rice K, Carmichael J, Murray JC. Prostate adenocarcinoma cells release the novel proinflammatory polypeptide EMAPII in response to stress. Cancer Res (2000) 60(11):2850-7.

37. Ahn YH, Park S, Choi JJ, Park BK, Rhee KH, Kang E, et al. Secreted tryptophanyl-tRNA synthetase as a primary defence system against infection. Nat Microbiol (2016) 2:16191. doi: 10.1038/nmicrobiol.2016.191

38. Aarvak T, Chabaud M, Miossec P, Natvig JB. IL-17 is produced by some proinflammatory Th1/Th0 cells but not by Th2 cells. J Immunol (1999) 162 (3):1246-51.

39. Patil S, Pincas H, Seto J, Nudelman G, Nudelman I, Sealfon SC. Signaling network of dendritic cells in response to pathogens: a community-input supported knowledgebase. BMC Syst Biol (2010) 4:137. doi: 10.1186/17520509-4-137

40. Zhang YL, Dong C. MAP kinases in immune responses. Cell Mol Immunol (2005) 2(1):20-7. doi: 10.1146/annurev.immunol.20.091301.131133 
41. Zhang P, Martin M, Michalek SM, Katz J. Role of mitogen-activated protein kinases and NF-kappaB in the regulation of proinflammatory and antiinflammatory cytokines by Porphyromonas gingivalis hemagglutinin B. Infect Immun (2005) 73(7):3990-8. doi: 10.1128/IAI.73.7.3990-3998.2005

42. Yang Y, Kim SC, Yu T, Yi YS, Rhee MH, Sung GH, et al. Functional roles of p38 mitogen-activated protein kinase in macrophage-mediated inflammatory responses. Mediators Inflammation (2014) 2014:352371. doi: 10.1155/2014/352371

43. Young HJ, Lee JW, Kim S. Function of membranous lysyl-tRNA synthetase and its implication for tumorigenesis. Biochim Biophys Acta (2016) 1864 (12):1707-13. doi: 10.1016/j.bbapap.2016.09.009

44. Cho HY, Ul Mushtaq A, Lee JY, Kim DG, Seok MS, Jang M, et al. Characterization of the interaction between lysyl-tRNA synthetase and laminin receptor by NMR. FEBS Lett (2014) 588(17):2851-8. doi: 10.1016/j.febslet.2014.06.048

45. Waithman J, Mintern JD. Dendritic cells and influenza A virus infection. Virulence (2012) 3(7):603-8. doi: 10.4161/viru.21864
46. Palomino-Segura M, Perez L, Farsakoglu Y, Virgilio T, Latino I, D’Antuono R, et al. Protection against influenza infection requires early recognition by inflammatory dendritic cells through C-type lectin receptor SIGN-R1. Nat Microbiol (2019) 4(11):1930-40. doi: 10.1038/s41564-019-0506-6

Conflict of Interest: The authors declare that the research was conducted in the absence of any commercial or financial relationships that could be construed as a potential conflict of interest.

Copyright (c) 2020 Jung, Park, Cho, Jung, Cho and Kim. This is an open-access article distributed under the terms of the Creative Commons Attribution License (CC BY).

The use, distribution or reproduction in other forums is permitted, provided the original author(s) and the copyright owner(s) are credited and that the original publication in this journal is cited, in accordance with accepted academic practice. No use, distribution or reproduction is permitted which does not comply with these terms. 